How to cite this article:

Ali, A., Farooq, W., \& Khalid, M. A. (2020). The relationship between organisational climate for innovation and innovative work behaviour: Mediating role of employee engagement in Pakistan. Malaysian Management Journal, Vol. 24(July), 195-218. https://doi.org/10.32890/mmj.24.2020.8776

\title{
THE RELATIONSHIP BETWEEN ORGANISATIONAL CLIMATE FOR INNOVATION AND INNOVATIVE WORK BEHAVIOUR: MEDIATING ROLE OF EMPLOYEE ENGAGEMENT IN PAKISTAN
}

\author{
ASIF ALI * \\ WAQAS FAROOQ \\ MUHAMMAD AHSAN KHALID \\ University of Management and Technology Lahore, Pakistan \\ *Corresponding author: rajaasif92@gmail.com
}

\begin{abstract}
The purpose of this study is to empirically investigate the mediating result of employee engagement between organisational climate for innovation and innovative work behaviour. This study will have positive contribution towards theory. The tool used for data collection was closed-ended questionnaire. Results indicated that organisational climate for innovation and innovative work behaviour has a direct and indirect impact on innovative work behaviours. In this study, employee engagement has partial mediation impact between the organisational climate for innovation and innovative work behaviour. Approximately, 210 respondents participated in this study. The unit of analysis used in this study was employees. For practical implication, it will be useful for HR specialists who are concerned in increasing successful intercession that encourage employees to engage in innovative work behaviour. This paper offers contribution to the understanding of the relationship between the innovative work behaviour and organisational climate and mediating role of employee engagement.


Keywords: Employees' innovative behaviour, employee engagement, organisational climate. innovation, Pakistan.

Received: 13/2/2020 Revised: 1/7/2020 Accepted: 6/8/2020 Published: 30/8/2020

\section{Introduction}

According to the "Community Innovation Survey" which was conducted in Europe (2015), an estimation of approximately 50 percent of the companies are having innovative work environment and that these companies appreciate their employees to "think out of the box" (Mishra, Bhatnagar, Gupta \& Wadsworth, 2017).

According to Global Innovation Index (2014), innovation plays a vital role in economic strength and business welfare as well as for the emerging economies. Due to the innovative work behaviour (IWB), organisational performance (OP) needs to be raised to new heights. In this way, it can gain competitive advantage in rather a short time. Researchers believe that employees are the backbone of the companies in promoting innovative environment at the workplace (Anderson, Potočnik \& Zhou, 2014; Janssen, Van de Vliert \& West, 2004; Oldham \& Cummings, 1996; Scott \& Bruce, 1994). Researchers are now forced to develop individual innovation which will be better for organisational achievements (Jafri, 2010; Wojtczuk-Turek $\&$ Turek, 2015). IWB focuses on thinking of employees; as such, it tries to help them to develop IWB in one's work in different ways and how to improve their abilities as well as to look for new and suitable technologies (Pukienè, 2016).

Any organisation implements innovative process with creative ideas, thinking and foreseeing new problem-solving methods at an individual level will be able to gain sustainability in the market (Foss, Lyngsie \& Zahra, 2013). According to Scot and Bruce (1994) and Jannssen (2000), in anticipating the IWB during working environment, it shows that multifaceted employee behaviour consists of three different behavioural tasks such as idea generation, idea promotion and idea realisation. At the individual level, innovation process starts with idea generation, as such, this is the work of fiction, thoughts and suggestion in every aspect (Inkinen, Kianto \& Vanhala, 2015). Furthermore, current research work suggests keeping these stages of innovation separate with one another (Duran, Kammerlander, Van Essen \& Zellweger, 2016; Mumford \& Licuanan, 2004).

According to Janssen et al. (2004) and Spanuth and Wald (2017), who have paid more concentration on the factors at the organisational and individual 
levels, which potentially endorse employees' IWB. Theoretically, the outcome sheds light on conflicting results regarding the association between organisational climate for innovation (OCI) and employees' IWB (De Jong \& Den Hartog, 2007; Khalili, 2016). There may be OCI and its effect on IWB through individual level mediators. Thus, it is important to reveal the problem and develop a question on this relation and link it with individual potential mediator, like as 'employee engagement (Shanker, Bhanugopan, Van der Heijden \& Farrell, 2017). This relation will also present theoretical framework which helps to reveal that workers engagement can be a positive interpreter of IWB.

\section{Literature Review}

\section{Innovative Work Behaviour}

The assessments of the employees' IWB have become a very important task for Human Resource Practitioners (Amabile \& Pratt, 2016). Many theorists have focused on the significance of innovation process within the perspective of HRM and also according to the organisational and employees' behaviour (Axtell et al., 2000; Sanz-Valle \& Jiménez-Jiménez, 2018; Scott \& Bruce, 1994).

The researchers have explained the process of innovation which consists the two main stages such as the beginning and the accomplishment (Axtell et al., 2000; Tamayo-Torres, Gutiérrez-Gutiérrez, Llorens-Montes \& Martínez-López, 2016; Zaltman, Duncan \& Holbek, 1973). The first phase of innovation process is completed through the generation of an idea; on the other hand the other phase is completed until the implementation of the idea (King \& Anderson, 2002). The next stage of innovation process reveals the idea of promotion. If an employee generates innovative idea, then that the employee will engage in social and routine activities with colleagues and friends to ideas on who will provide important suggestions and authentic visions (Afsar, Badir \& Bin Saeed, 2014; Galbraith, 1982; Moss Kanter, 1983). The innovation system relates with the idea realisation by generating a test product regarding creativity which will be capable of having more skilled workers at the end; thus, it is very helpful at the individual or at the organisational level (Moss Kanter, 1988).

Literature tends to differentiate the IWB from creativity (Amabile, 1988; De Jong \& Den Hartog, 2010). According to this concept, it shows that innovative work behaviour not only generates new thoughts or ideas but also endorses reality regarding those new ideas which are very important for organisational performance (De Jong \& Den Hartog, 2010). Therefore, 
many researchers concluded that creativity is only a single piece of the action about IWB (De Jong \& Den Hartog, 2010; Janssen et al., 2004), because IWB consists of 'a multi-stage process' (Janssen, 2000; Moss Kanter, 1988) such as producing ideas, promoting ideas and implementing new thoughts (Janssen, Van de Vliert, \& West, 2004).

Unnoticed ideas in the perspective of IWB have come into existence due to current problems containing high level of risks, which cannot be solved at the individual level (Scott \& Bruce, 1994). Sometimes their ideas regarding innovation may put their current positions and rewards into danger within the organisation (Jansen et al., 2004). Employees who are more talented decrease the level of risk due to Innovative work behaviour (Chen \& Aryee, 2007).

IWB is not a compulsory component of the every employee during work place. IWB of the employee is additional role behaviour, which tells about the employee's less rigid behaviour which is not associated with employee job description (Katz \& Kahn, 1978). The employees' IWB is very important for the current management rules and regulation; for instance, continuous improvement of the organisation (Fuller, Marler, \& Hester, 2006) and (Imai, 1986) business private enterprise (Chua, Chrisman, \& Sharma, 1999) and implication programmes (Unsworth, 2001). The companies focus on the employees' IWB, and invest more on their employees for the enhancement of IWB in order to survive for a long time and also to accomplish the company's goals in the competitive environment.

\section{Employee Engagement}

Employee engagement is also a very important subject in the field of organisation development (Shuck \& Wollard, 2010). The reviewed literature demonstrates that employees engagement has become a very interesting issue in recent decades (Albrecht \& Albrecht, 2010). The only one empirically studied has been examined by Kahn's (1990) on an idea regarding employees engagement which was directed by May, Gilson and Harter, (2004), demonstrate that every one of the three of Kahn's (1990) mental circumstances was emphatically identified with the advancement of engagement in a working environment. The most cited and widely read reading paper presented in (2012) on employee engagement by Harter et al., where these researchers adopted 7939 business units (Harter, Schmidt, \& Hayes, 2002) to assess the benefits of employee engagement. The researchers agreed with Kahn's concept (1990) in their meta-analysis; they claimed that engagement occured when the employees were cognitively and emotionally attached to their work responsibility. 
According to Kahn (1990, p. 694), who introduced the perception of employee engagement (1990), employee engagement refers to "the harnessing of organization members' selves to their work roles; in engagement, people employ and express themselves physically, cognitively, and emotionally during role performances."

Furthermore, Kahn (1990) added three situations with respect to the psychological engagement which is very important for all employees to engage themselves at the high level in the right way such as significant work components, wellbeing and social components. Kahn viewed the personal engagement regarding employees to enhance performance effectively, physically, mentally and emotionally involves them in work. If workers are not engaged in work then they are not ready to perform well mentally, physically and emotionally (Kahn, 1990).

Employees perform well which results to the increase of engagement level if they are mentally engaged in working time. Employee engagement (EE) has three perspectives; (i) vigour is viewed as having high levels of energy and mental resilience, (ii) dedication is viewed as being strongly involved in one's work and experiencing a sense of significance, enthusiasm and challenge, and (iii) absorption is viewed as being fully focused and happily engrossed in one's work (Bakker \& Demerouti, 2008; Schaufeli \& Bakker, 2004). Kahn's framework provides the researchers a significant framework of an employee's enthusiasm to engage a standard limitation (Cole et al., 2012; Rich, Lepine \& Crawford, 2010).

\section{Organization Climate for Innovation}

Innovation has been pointed out as the main capability for current organisations to overcome the challenges and enhance performance efficiently and effectively which demands quick changing and has been in competition in today's environments (Bledow et al., 2009; Choi \& Chang, 2009; Hansen \& Levine, 2009). Many studies have pointed out the significance of elements which affects the organisational climate which, in turn, can promote creativity, encourage employee innovative work behaviour and make a smooth run in the innovation process (Amabile, Conti, Coon, Lazenby, \& Herron, 1996; Berkhout, Hartmann, Van Der Duin, \& Ortt, 2006; Steele \& Murray, 2004). The previous studies on the organisational and group level revealed a positive impression of OCI (Amabile et al., 1996; Nijhof, Krabbendam \& Looise, 2002; West \& Anderson, 1996).

Organisational climate is the most significant element of innovation which is very important in helping and constraining special effect toward the triumphant 
implementation and innovation maintenance process (Ahmed, 1998). These successful effects were well explained by Martins and Terblanche, (2003) and gave significant results from the process of organizational socializations which establishes shared values and norms for the formation of employees' behaviour and activities which reflect the organisation's strategies, polices procedures and practices.

A wide range of innovative organisations were busy to find a maximum level of freedom and self-efficacy to reduce the element of risk and create an environment which has a capacity to bear the risk (Amabile et al., 1996; Egbu et al., 1998; E. Martins \& F. Terblanche, 2003; Steele \& Murray, 2004). This type of organization, creativity process is supported, encouraged and innovation efforts are accepted and praised innovative climate (Amabile et al., 1996; Berkhout et al., 2006; Chandler, Keller, \& Lyon, 2000; Ekvall, 1996).

Internal environment of any organization which is very supportive in innovation which turns into as organizational climate for innovation and it's very essential for organizational leveraging which is regarding to innovativeness for the creation of a competitive advantage to achieve goals and to enhance organizational performance (Kissi, Dainty, \& Liu, 2012). The organisational climate for innovation determines the norm, values and practices which encourage employees elasticity and expression regarding their ideas and learning (Van der Vegt, Van de Vliert, \& Huang, 2005).

Only those employees will be empowered when they work in an innovative climate and perform well by their innovative ideas. It is essential to create such a climate which developes the employees thinking skills converning decision-making or the management and organization which they observed, and not caring about what they said before the higher management (Kissi et al., 2012). Therefore, organisational atmosphere can draw a very crucial result on the inspiration and innovation process inside the company (Amabile et al., 1996; Nybakk, Crespell, \& Hansen, 2011).

\section{Organizational Climate for Innovation and Innovative Work Behaviour}

According to De Jong (2006) who conducted interviews with managers and leaders of different firms; particularly, those in the knowledge-intensive services firms, organization (OCI) is an antecedent of IWB. West and Rickards (1999) reported that employee creativity and innovative work behaviour are promoted by the factors regarding working environment and personal qualities. Significantly, Huhtala and Parzefall (2007) explained that 
when compare routine job task with non-routine daily task and employee working conditions are more challenging and then need for more creative consideration for the growth and learning of individual personality and which further promotes innovativeness among the employees. Even if there is a strong significant correlation among the innovative climate and innovative work behaviour, it is revealed that the organisational innovative climate has strong effects on the entire organisational and the team's innovative behaviours (De Jong \& Den Hartog, 2007).

A few researches with respect to the impacts of organisational climate for innovation on individual level IWB have been exceptionally lacking. As indicated by Scott and Bruce, (1994), guessed that the impression of organisational climate influenced IWB, and found a positive yet rather frail relationship. According to (Krause, 2007) organisational climate magnitudes such as job autonomy and employees' freedom in addition to preamble of particular knowledge and information come in to views to have a positive impact on the IWB. Exclusively, individuals who perform in that environment where there are thought to have an existence of independence environment which will then perform very well they perform well to impose their new innovative ideas and they will have a greater command on their work for the enhancement of innovative behaviour (Amabile et al., 1996; Si \& Wei, 2012).

Albrecht and Hall (1991), for instance, concluded that implementing new ideas practically was supposed to be more risky and reasonable that it will create chaos to an established order. Consequently, due to the inability to acquire new ideas and the fear of submitting new ideas as foreign then the process of creativity is encouraged. When individuals see such strong practice and so on, they trust that the association esteems development and thus would feel roused to enhance innovative work behaviour (Ahmed, 1998; Berkhout et al., 2006). Such social observation has in this way turn into an essential to innovative behaviour.

$\mathrm{H}_{1}$ : Organisational climate for innovation is related to innovative work behaviour.

\section{Employee Engagement and Innovative Work Behaviour}

Employees' innovative work behaviours premeditated formation, preamble and function of fresh ideas within a working environment or organization to be at an advantage of carrying at a job presentation, as in a team-based, or an organizational-base of work (West \& Far, 1989). The main function of innovation is continuing survival (Ancona \& Caldwell, 1987). 
Inadequate struggle has been made to scrutinize employee engagement as in the same as precursor of innovativeness (Hakanen, Perhoniemi, \& Toppinen-Tanner, 2008). Sometimes, organizations introduce innovation to make available advantages (West \& Farr, 1989), but there is a need to adopt innovation process which demands more investments on their employees for providing crucial efforts. In view of the fact that employees innovative work behavior is the name of creating something new which did not exist before, which is then the reason for managers wanting employees pay full attention and be fully engaged in work role and becoming immersed in their work (Woodman, Sawyer, \& Griffin, 1993).

To steadily invest in employee engagement, an individual must identify what she is doing and also know about what she invest extra struggle. Only individuals who could do it and pay full attention towards change and also concentrate on their working environment (dedication). Absorption is "being fully concentrated and deeply engrossed in work." Vigorous "high levels of energy and mental resilience, and persistence even in the face of difficulties" and devotion required to construct an innovative occupation method the hub measurements of employee engagement. Bakker et al. (2007) discovered optimistic connections flanked by innovative work behaviour and the employees' engagement.

$\mathrm{H}_{2}$ : Employee engagement is related to innovative work behaviour.

\section{Organisational Climate for Innovation and Employee Engagement}

An organisational climate implies that the characteristics and the conviction structure that are not unmistakable but instead exist inside the delegate's conduct, motive as well as action which effect their job satisfactions (Moghimi \& Subramaniam, 2013).

The organisational climate is the perception and interpretation by the employees of their environments or the organizational context is defined as the perceptual and experiential component resulting from mutual interaction between the organizational environment and the employees engagement (Brown \& Leigh, 1996). Given that, engaged representatives, typically have positive mental encounters and inspirational states of mind, may be normal that such laborers have constructive outcome on an authoritative atmosphere (Wollard \& Shuck, 2011). Various inquires reinforce the likelihood of the effect of organisational climate on the difference in work setting that enables employees' engagement and inspiring states of mind at work, which could be connected with organisational wellness (Wagner \& Harter, 2006).

In this good judgment, employees engagement impacts the work setting and is influenced by it; employees who are engaged have sound relational skills 
which is a major contribution in the production of significant organisational climate (Cameron, Dutton, Quinn, \& Wrzesniewski, 2003) which have a tendency to be helpful for the improvement of the engagement. Employees with increased amounts of engagement will probably set up great connections with bosses, associates and show demeanors, intentions and positive practices (Saks, 2006), while encountering positive feelings all the more often (Bakker, Albrecht, \& Leiter, 2011; Bindl \& Parker, 2010). Despite the recognition of the importance of worker engagement and organizational climate for organizational effectiveness, there is not yet enough research to understand the relationship between these constructs. Recently Kataria et al., (2013), found that apparent organisational climate described by protected and significant workplaces (i.e. hold up by directives, parts lucidity, probability to express naturally affirmation and plausibility to take an interest in the results) are emphatically identified with representative work engagement, which is particularly identified with organizational effectiveness.

$\mathrm{H}_{3}$ : Organizational climate for innovation is related to the employee engagement.

\section{Mediating Effect of Employee Engagement}

The mediating impact of employee engagement between the organisational components and its results has been shown in many studies. Bakker and Bal (2010) investigated that employee's engagement completely mediate the connection amongst self-rule and employment job presentation. Salanova, Agut and Peiró (2005) demonstrated that employee engagement mediated the effect of organisational possessions on organisational climate. Meanwhile, Sallanova and Schaufelli (2008) established that employees' engagement completely mediates the association between action resources (work organised, criticisms and assortment) and practical behaviour at work. Saks (2006) likewise uncovered that employees engagement, partially mediates the connection flanked by the components of worker engagement (work attributes, apparent organisational hold up, apparent mentor help, prizes and acknowledgment, procedural equity, and distributive equity) and results of worker engagement (work fulfillment, executive responsibility, aim to stop).

According to Venarski Peretz and Carmelli's (2011) contemplation exhibited that significant mental situation, for example, employee's engagement and advance IWB. Binnewies et al. (2007) announced that one-person activity is significantly identified with idea creative process. That is why employee 
engagement assumes a key part in the development procedure as far as producing vitality for stepping up (Park et al., 2014).

From a theoretical point of view, the outcomes give ways towards the conflicting discoveries of De Jong and Den Hartog (2007) and Krause, (2007) as to the link between organizational climate for innovation and innovative work behaviour. Furthermore, the exploration shows line up with Yeoh and Mahmood (2013) who discovered a significant connection among an OCI and worker IWB.

A generous group of investigators has featured the centrality of intrinsic motivation in IWB (Amabile et al., 1996; Dulaimi, Nepal, \& Park, 2005). With respect to intrinsic motivation theory sets that people are more propelled by the sentiment ability and fulfillment got commencing the assignment itself as opposed to outside prizes (e.g., cash and acclaim); along these lines, people's requirement for self-assurance drives objective coordinated conduct and encourages them to conquer challenges (Deci \& Ryan, 1985). Amabile (1996) well thought-out intrinsic motivation a major segment of inventive work behaviour since positive behaviour and solid mental strength got from employees who are important to manage deadlines that emerge in the development procedure. Individuals engaged employees who are energetic, passionate, and immersed in their work because they enjoy their accomplishment at workplace. In this study, OCI has direct relation on innovative work behaviour, the employee engagement has direct relation on IWB and that the OCI has direct relation on employee engagement. As such, EE tends to mediate the relationship of organisational climate for innovation and IWB.

$\mathrm{H}_{4}$ : The relationship between organisational climate for innovation and innovative work behaviour is mediated by the employee engagement.

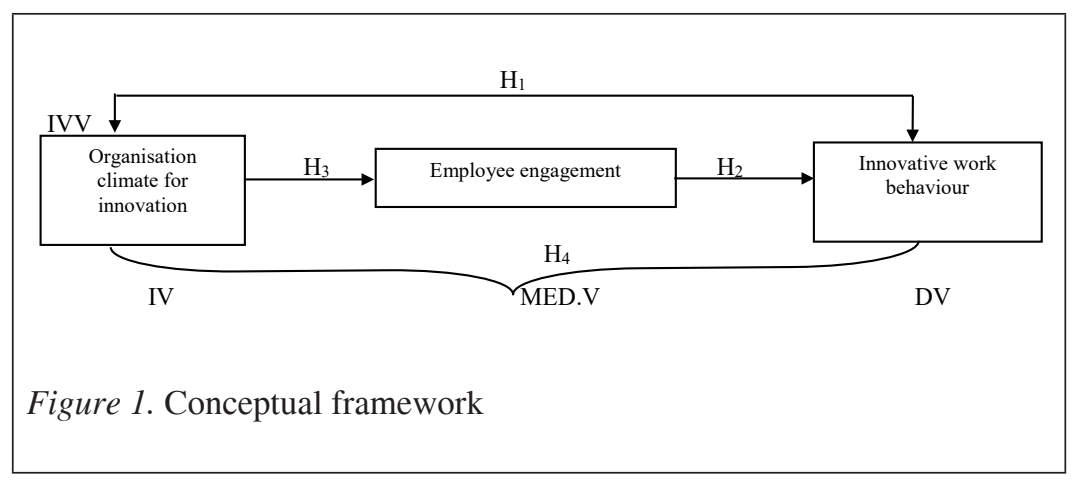




\section{Methodology}

A quantitative methodology is used in the form of statistical analysis derived from the employee' engagement, employee innovative work behaviour and organisational climate for innovation questionnaires. OCI develop utilised as a part of this investigation, is estimated by the Isaksen, Lauer, and Ekvall (1999). It was based on the OCI created by Ekvall (1983) which comprised nine items. Supervisors were asked to fill the evident climate for development as indicated by their relationship on a five-point Likert scale. Every item begins from 'not at all applicable' to 'frequently applicable'. The IWB was estimated by executing Janssen's (2000) scale which comprised three phases of advancement: (i) the idea generation (three items), (ii) the idea promotion (three items) and (iii) the idea realisation (three items). All items in the scale were measured using a five-point rating scale ranging from 'never' to 'always'. To measure the employee engagement level (UWES-9), a short version of the Utrecht Work Engagement developed by Schaufeli and Bakker (2003) was used which had seventeen items. All scales were originally developed in English language. The five-point Likert scale was used where 1 denoted "strongly disagree," and 5 denoted "strongly agree". The Likert scale was used as it was easier to answer, took less time of the respondents (Frazer \& Lawley, 2000) and offered a high likelihood of responses that would accurately reflect the respondents' opinions (Zikmund, 2010).

\section{Results}

\section{Descriptive Statistics}

We mailed and personally met with related individuals to fill-up questionnaires from manufacturing and services industries in Lahore. For this study, 248 questionnaires were distributed and only 210 responses were received, whilst 13 individuals did not participate in this research. Approximately 25 respondents partially filled the questionnaire which led us to discard the responses. The response rate is 84.68 percent. Analysis was done using the descriptive statistics, regression analysis, correlation analysis and mediation analysis. Descriptive statistics was used to check the frequencies of demographic variables. It was also used to confirm the mean and standard deviations of variables. Correlation was performed to check the associations involving variables. Regression was performed to check the effect of variables and to confirm the hypothesis. To prove the mediator, mediation analysis was performed. Table 1 shows the number of organisations selected and the number of samples from each sector. 
Table 1

Industry in Sample

\begin{tabular}{lcc}
\hline Sectors & Number of companies & Samples \\
\hline Manufacturing & 8 & 141 \\
Services & 11 & 69 \\
Total & 19 & 210 \\
\hline
\end{tabular}

\section{Reliability Analysis}

Table 2 presents the Cronbach's alpha coefficient for variables of this research. The Cronbach's alpha coefficient value for the IWB is 0.73 . Cronbach's alpha coefficient value for the EE is 0.91. Cronbach's alpha coefficient value for the organisational climate for innovation is 0.61 . Hair et al. (1998) suggested that the Cronbach's alpha value of 0.61 and above should be acceptable.

Table 2

Modified Cronbach's Alpha

\begin{tabular}{lcc}
\hline Components & No. of items & Cronbach's Alpha \\
\hline IWB & 9 & 0.73 \\
EE & 17 & 0.91 \\
OCI & 9 & 0.61 \\
\hline
\end{tabular}

Table 3 explains the mean, standard deviation and correlation of the constructs. The mean value of the employee engagement is 3.679 , the mean value of the organisational climate for innovation is 3.3021 and the mean value of IWB is 3.560. The standard deviation value of employee engagement is 0.498 , the organisational climate for innovation is 0.535 and for the IWB is 0.588 . The employee engagement positively correlates with the organisational climate for innovation which is $0.351 * *$ and with IWB it is $0.336^{* *}$. The IWB positively correlates with the organisational climate for innovation $\left(0.375^{* *}\right)$. 
Table 3

Means, SD and Correlation of the Variables

\begin{tabular}{lccccc}
\hline & Mean & SD & 1 & 2 & 3 \\
\hline Employee engagement & 3.679 & 0.498 & 1.00 & & \\
Org. climate for innovation & 3.302 & 0.535 & $0.351^{* *}$ & 1.00 & \\
Innovative work behaviour & 3.560 & 0.588 & $0.336^{* *}$ & $0.375^{* *}$ & 1.00 \\
\hline Note: $* * *, * *$, and $*$ denote statistically & significance at $1 \%, 5 \%$ and $10 \%$ level of
\end{tabular}
significance.

As shown in the Table 4, the results indicate that the total variation explained in IWB due to OCI and EE is 0.188 or 18.8 percent as indicated by r-square value. The regression analysis indicates that the EE and OCI significantly ( $p$ $\leq 0.000)$ and positively $\left(\mathrm{R}^{2}\right.$ value 0.276 and $p$ value 0.432$)$ impact the IWB respectively. Thus, such results provide support for hypothesis $H_{1}$ and $H_{2}$, therefore, hypothesis $\mathrm{H}_{1}$ and $\mathrm{H}_{2}$ are accepted.

$\mathrm{H}_{1}$ : The organisational climate for innovation is positively related to innovative work behaviour.

$\mathrm{H}_{2}$ : The employee engagement is positively related to innovative work behaviour.

Table 4

Test of Hypotheses

\begin{tabular}{lllllll}
\hline Model summary & \multicolumn{7}{c}{ Outcome IWB } \\
\hline $\mathrm{R}$ & $\mathrm{R}^{2}$ & $\mathrm{MSE}$ & $\mathrm{F}$ & $\mathrm{df1}$ & $\mathrm{df} 2$ & $p$ \\
0.4340 & 0.188 & 0.284 & 24.016 & 2.000 & 207.00 & 0.000 \\
Model coefficient & $\mathrm{Se}$ & $\beta$ & $t$ & $p$ & LLCI & ULCI \\
Constant & 1.4816 & 3086 & 4.8007 & 0.0000 & 0.873 & 2.0901 \\
LE & 0.276 & 0.079 & 3.492 & 0.0006 & 0.120 & 0.432 \\
OCI & 0.322 & 0.074 & 4.381 & 0.0000 & 0.177 & 0.467 \\
\hline
\end{tabular}

Table 5 indicates that $\mathrm{F}$ value is significant which indicates that the model is fit for analysis and that the total variation explained in EE due to OCI is $\mathrm{R}^{2}=0.123$, or 12.3 percent. Furthermore, the OCI influences EE positively with $\beta=0.327$ with significance $p<0.001$, thus providing support for third hypothesis which states that: 
$\mathrm{H}_{3}$ : Organisational climate for innovation is positively related to the employee engagement.

Table 5

Model Summary Outcome: EE

\begin{tabular}{lllllll}
\hline $\mathrm{R}$ & $\mathrm{R}^{2}$ & $\mathrm{MSE}$ & $\mathrm{F}$ & $\mathrm{df1}$ & $\mathrm{df} 2$ & $p$ \\
\hline 0.351 & 0.123 & 0.219 & 29.185 & 1.000 & 208.000 & 0.000 \\
Model & & & & & & \\
& Coefficient & $\mathrm{SeB}$ & $t$ & $p$ & LLCI & ULCI \\
Constant & 2.600 & 0.202 & 12.852 & 0.000 & 2.201 & 2.999 \\
OCI & 0.327 & 0.061 & 5.402 & 0.000 & 0.206 & 0.446 \\
\hline
\end{tabular}

Following Hayes (2008), the mediation analysis results, shown in Table 6 , indicate direct and indirect effect of OCI on IWB through employee engagement. Since Direct effect (OCI->IWB) value is 0.322 and $p$ value is significant, and indirect effect (OCI->IWB) value is 0.090 which is also significant (CI: $0.034-0.168$ ) and the effected size significantly reduces in the indirect effect as compared to direct effect, so this is partial mediation as shown in the Table 6 therefore $\mathrm{H}_{4}$ is partially accepted.

$\mathrm{H}_{4}$ : The relationship between organisational climate for innovation and innovative work behaviour is partially mediated by the employee engagement.

Table 6

Direct Effect of $X$ on $Y$

\begin{tabular}{llllll}
\hline Effect & SE & $t$ & $p$ & LLCI & ULCI \\
\hline 0.322 & 0.074 & 4.381 & 0.000 & 0.177 & 0.467 \\
Indirect effect of X on Y & & & & & \\
& Effect & Boot SE & Boot LLCI & Boot ULCI & \\
EE & 0.090 & 0.034 & 0.034 & 0.168 & \\
\hline
\end{tabular}

\section{Discussion}

The reason for this study is to investigate and broaden the exploration on individual IWB by giving associations more viable approach to execute 
OCI and for worker engagement. This study was conducted to check the relation between OCI, workers engagement and IWB and also, the mediating consequence of employee engagement between OCI and IWB.

The findings support the relationship between OCI and IWB which was considerable. This demonstrates the presence of an inventive tradition that it plays a causative part in improving the IWB. The consequences facilitate previous researches that contain IWB (e.g., Kisi et al., 2012; Karause, 2007). In previous studies, the current study supports the relation between the individual IWB and OCI (Amabile \& Gryskiewicz, 1989; Jaskyte \& Kisieliene, 2006; Oldham \& Cummings, 1996). Earlier examinations revealed little research identifying with the impact of demographic factors on IWB and OCI. According to the findings, OCI has direct effect on IWB. Thus, this study has achieved the first objective, that is, OCI has positive impact on the innovative work behaviour.

Employees engaged in IWB will be able to promote organisational effectiveness (Borman \& Motowidlo, 1997). There is the need to understand the fact that suitable organisational climate for innovation can better engage employees through human resource management which will have positive impacts on the firm's performance. Employee's innovative work behaviour is recognised as an important factor for organisational success (Chua et al., 1999; De Jong \& Den Hartog, 2007; Janssen, 2000; Scott \& Bruce, 1994; Van de Ven, 1986).

The results have proved that OCI has significant impact on employee engagement. According to Krause (2007), employees are expected to be involved in IWB when they are allowed to have more freedom and autonomy because it gives power to the employees to control and improve the working environment by enhancing the power of innovativeness. In addition to that, Odoardi, Battistelli and Montani (2010) observed that employees see their workplace as a place where their ideas are appreciated and their creativity and innovative ideas are accepted. They will be more up to the mark, more engaged and eagerly accepting the targets which are related to innovation.

Important contribution of the research is to make available the initial empirical research connecting the organisational climate for innovation and employee engagement to discover IWB. In particular, the investigation additionally utilised the interceding impact of employee engagement on the connection amongst OCI and IWB. Also in the previous study, it showed the connection between OCI and organisational performance and it was mediated by IWB (Shanker et al., 2017). The verdicts of this research showed reliable 
findings accords industries (control variable has no significant coefficients) and therefore, they can be generalisable. Findings of this study have some implication for the organisation. OCI have to realise the significance of suitable climate for innovation regarding employees' engagement to enhance innovative work behaviour which will be able to give the organisation the competitive edge.

\section{Implications for Practice}

This examination has strong ramifications for supervisors who are willing to support or extend a strong and positive OCI to gain stable IWB among employees. As far as managers who are at the top level of the other organisations are concerned, they must be aware of the situation when they need to push their employees to think out of the box and to revive innovation in their workplace. Therefore, the practical implication for this study is pointed towards the role of the organisations and specifically the HR managers, in creating a motivating, well-informed and innovative work environment. This study also posit that HR managers and instantaneous supervisors should have the power to relieve the negative vibes of knowledge sharing on IWB by aligning the advance climate in the course of proceedings and positive attitude towards innovation (McGuirk, Lenihan \& Hart, 2015).

These findings have some stimulating implication for practitioners whose target is to develop OCI for individual engagements. The human resource managerial policies should be adjusted with organisational target for advancement while keeping in mind the organisational performance. This would include new policies, systems and structures where employees have the autonomy while doing their work and fare recognised when positive behaviour is connected with innovativeness.

To develop a sustainable atmosphere, in particular, for innovativeness to prosper, the top executives might give training to their managers to make them more proactive and supportive, and in return, support the team dynamics where idea sharing and "think out of the box" is practiced and implemented. Therefore, the current research has shown the importance towards building the foundation of organisational climate and innovative agenda by providing the support towards the employee engagement and its role on innovative work behaviour. Also, employees assigned on different jobs who do not have direct link with innovation in the organisation must cooperate with the others and they still can be precious to the organisational performance and innovative behaviour even if theyhave non-adjustable attitudes. 


\section{Limitations and Future Research}

There is a growing body of literature on innovation, however, studies on the role of organisational climate for innovation and also employee engagement in triggering individual innovative work behaviour have been rarely explored. In pursuing such research, there have been several limitations.

The initial limitation of this study is related to the study design because the data gathered were obtained from employees working in the manufacturing and service sectors located in Lahore (Pakistan). The sample size provides satisfactory results based on the cross-sectional study but a longitudinal study can also be used to get more adequate results. Qualitative research is tentative in nature; its methodology allows for a richer and detailed data.

According to Amabile (1996), intrinsic motivation is important for innovative work behaviour because having positive behaviour, strong mental ability and adjusting according to the dynamic environment is essential to cope up with any situation that occurs because of innovation process. This study suggests that employee's engagement supports innovative behaviour with the help of organisational climate for innovation. The main focus of this study is to check the connection between variable while excluding the control variable, that is, demographic information to ensure that future research can also include demographic information for more appropriate result.

In this study, the employee engagement is included as mediator while excluding other variables such as intrinsic motivation (Shanker et al., 2017) between the relationship OCI and IWB. Furthermore, transformational leadership style can be taken as the independent variable between employee engagement and innovative work behaviour and also other characteristics can be included for future research. Last but not the least, the organisational culture can be taken as moderator for future exploration because this methodology allows richer and more in-depth understanding of the phenomenon and also examines the complex questions that are impossible with quantitative method.

\section{Conclusion}

To summarize, the current research aims at proposing a mediation framework to elucidate OCI through mediation of employee engagement as a key factor for enhancing IWB. Given the present business condition that continually requests new and modified items, improving employee innovative work behaviours will create an impression of being of superseding significance. The principle of the study was to build upon and broaden the existing 
investigations on individual IWB by contributing a positive way for organisations to encourage organisational climate for innovation and their worker engagement. This research consequence showed that individual, IWB is prejudiced by the organisational climate for innovation through employee engagement.

Findings have revealed that simple relationships between OCI and IWB should not be assumed. OCI has to rely on employee engagement to improve IWB. Only OCI is not sufficed to bring forth the employee IWB. To achieve competitive advantage organisations need to develop a close relationship between OCI and IWB. Specifically, the study proposes that the organisational climate for innovation and innovative work behaviour alone are not adequate without its individuals' full contribution and duty and work engagement. Consequently, organisations need to consider how different segments of the organisational climate for innovation can be lined up with worker engagement and give the emotionally fundamental supportive networks to build up their workers' innovative work behaviour ability.

\section{Acknowledgement}

This research received no specific grant from any funding agency.

\section{References}

Afsar, B., F. Badir, Y., \& Bin Saeed, B. (2014). Transformational leadership and innovative work behavior. Industrial Management \& Data Systems, 114(8), 1270-1300.

Ahmed, P. K. (1998). Culture and climate for innovation. European Journal of Innovation Management, 1(1), 30-43.

Albrecht, S. L., \& Albrecht, S. (2010). Handbook of employee engagement. Edward Elgar: Publishing Limited Cheltenham.

Amabile, T. M. (1988). A model of creativity and innovation in organizations. Research in organizational behavior, 10(1), 123-167.

Amabile, T. M., Conti, R., Coon, H., Lazenby, J., \& Herron, M. (1996). Assessing the work environment for creativity. Academy of Management Journal, 39(5), 1154-1184.

Amabile, T. M., \& Gryskiewicz, N. D. (1989). The creative environment scales: Work environment inventory. Creativity Research Journal, 2(4), 231-253. 
Amabile, T. M., \& Pratt, M. G. (2016). The dynamic componential model of creativity and innovation in organizations: Making progress, making meaning. Research in Organizational Behavior, 36, 157-183.

Ancona, D., \& Caldwell, D. (1987). Management issues facing new product teams in high technology companies. Advances in Industrial and Labor Relations, 4, 191-221.

Anderson, N., Potočnik, K., \& Zhou, J. (2014). Innovation and creativity in organizations: A state-of-the-science review, prospective commentary, and guiding framework. Journal of Management, 40(5), 1297-1333.

Axtell, C. M., Holman, D. J., Unsworth, K. L., Wall, T. D., Waterson, P. E., \& Harrington, E. (2000). Shopfloor innovation: Facilitating the suggestion and implementation of ideas. Journal of Occupational and Organizational Psychology, 73(3), 265-285.

Bakker, A. B., Albrecht, S. L., \& Leiter, M. P. (2011). Key questions regarding work engagement. European Journal of Work and Organizational Psychology, 20(1), 4-28.

Bakker, A. B., \& Demerouti, E. (2008). Towards a model of work engagement. Career Development International, 13(3), 209-223.

Berkhout, A., Hartmann, D., Van Der Duin, P., \& Ortt, R. (2006). Innovating the innovation process. International Journal of Technology Management, 34(3-4), 390-404.

Bindl, U. K., \& Parker, S. K. (2010). 32 Feeling good and performing well? Psychological engagement and positive behaviors at work. In S. L. Albrecht (Ed), Handbook of employee engagement: Perspectives, issues, research and practice (pp 385-398). Edward Elgar: Publishing Limited Cheltenham.

Bledow, R., Frese, M., Anderson, N., Erez, M., \& Farr, J. (2009). A dialectic perspective on innovation: Conflicting demands, multiple pathways, and ambidexterity. Industrial and Organizational Psychology, 2(3), 305-337.

Borman, W. C., \& Motowidlo, S. J. (1997). Task performance and contextual performance: The meaning for personnel selection research. Human Performance, 10(2), 99-109.

Brown, S. P., \& Leigh, T. W. (1996). A new look at psychological climate and its relationship to job involvement, effort, and performance. Journal of Applied Psychology, 81(4), 358.

Chandler, G. N., Keller, C., \& Lyon, D. W. (2000). Unraveling the determinants and consequences of an innovation-supportive organizational culture. Entrepreneurship Theory and Practice, 25(1), 59-76. 
Chen, Z. X., \& Aryee, S. (2007). Delegation and employee work outcomes: An examination of the cultural context of mediating processes in China. Academy of Management Journal, 50(1), 226-238.

Choi, J. N., \& Chang, J. Y. (2009). Innovation implementation in the public sector: An integration of institutional and collective dynamics. Journal of Applied Psychology, 94(1), 245.

Chua, J. H., Chrisman, J. J., \& Sharma, P. (1999). Defining the family business by behavior. Entrepreneurship: Theory and Practice, 23(4), 19-19.

Cole, M. S., Walter, F., Bedeian, A. G., \& O'Boyle, E. H. (2012). Job burnout and employee engagement: A meta-analytic examination of construct proliferation. Journal of Management, 38(5), 1550-1581.

De Jong, J., \& Den Hartog, D. (2010). Measuring innovative work behaviour. Creativity and Innovation Management, 19(1), 23-36.

De Jong, J. P., \& Den Hartog, D. N. (2007). How leaders influence employees' innovative behaviour. European Journal of Innovation Management, 10(1), 41-64.

Deci, E. L., \& Ryan, R. M. (1985). The general causality orientations scale: Self-determination in personality. Journal of Research in Personality, 19(2), 109-134.

Dulaimi, M. F., Nepal, M. P., \& Park, M. (2005). A hierarchical structural model of assessing innovation and project performance. Construction Management and Economics, 23(6), 565-577.

Duran, P., Kammerlander, N., Van Essen, M., \& Zellweger, T. (2016). Doing more with less: Innovation input and output in family firms. Academy of Management Journal, 59(4), 1224-1264.

Egbu, C., Henry, J., Kaye, G., Quintas, P., Schumacher, T., \& Young, B. (1998). Managing organizational innovations in construction. Paper presented at the Proceedings of the 14th Annual Conference of the Association of Researchers in Construction Management (ARCOM), Reading. Retrieved from http://www.arcom.ac.uk/-docs/proceedings/ ar1998-605-614_Egbu_et_al.pdf

Ekvall, G. (1996). Organizational climate for creativity and innovation. European Journal of Work and Organizational Psychology, 5(1), 105-123.

Foss, N. J., Lyngsie, J., \& Zahra, S. A. (2013). The role of external knowledge sources and organizational design in the process of opportunity exploitation. Strategic Management Journal, 34(12), 1453-1471.

Fuller, J. B., Marler, L. E., \& Hester, K. (2006). Promoting felt responsibility for constructive change and proactive behavior: Exploring aspects of an elaborated model of work design. Journal of Organizational Behavior, 27(8), 1089-1120. 
Galbraith, J.R. (1982). Designing the innovating organization. Organizational Dynamics, 10(3), 5-25.

Hakanen, J. J., Perhoniemi, R., \& Toppinen-Tanner, S. (2008). Positive gain spirals at work: From job resources to work engagement, personal initiative and work-unit innovativeness. Journal of Vocational Behavior, 73(1), 78-91.

Hansen, T., \& Levine, J. M. (2009). Newcomers as change agents: Effects of newcomers' behavioral style and teams' performance optimism. Social Influence, 4(1), 46-61.

Harter, J. K., Schmidt, F. L., \& Hayes, T. L. (2002). Business-unit-level relationship between employee satisfaction, employee engagement, and business outcomes: A meta-analysis. Journal of Applied Psychology, 87(2), 268-279.

Imai, M. (1986). Kaizen: The key to Japan's competitive success. New York: McGraw-Hill Education.

Inkinen, H. T., Kianto, A., \& Vanhala, M. (2015). Knowledge management practices and innovation performance in Finland. Baltic Journal of Management, 10(4), 432-455.

Jafri, M. H. (2010). Organizational commitment and employee's innovative behavior: A study in retail sector. Journal of Management Research, $10(1), 62$.

Janssen, O. (2000). Job demands, perceptions of effort reward fairness and innovative work behaviour. Journal of Occupational and Organizational Psychology, 73(3), 287-302.

Janssen, O., Van de Vliert, E., \& West, M. (2004). The bright and dark sides of individual and group innovation: A special issue introduction. Journal of Organizational Behavior, 25(2), 129-145.

Jaskyte, K., \& Kisieliene, A. (2006). Determinants of employee creativity: A survey of Lithuanian nonprofit organizations. International Journal of Voluntary and Nonprofit Organizations, 17(2), 128.

Kanter, R. M. (1988). Three tiers for innovation research. Communication Research, 15(5), 509-523.

Katz, D., \& Kahn, R. L. (1978). Organizations and the system concept. Classics of Organization Theory, 161-172.

Khalili, A. (2016). Linking transformational leadership, creativity, innovation, and innovation-supportive climate. Management Decision, 54(9), 2277-2293.

King, N., \& Anderson, N. (2002). Managing innovation and change: A critical guide for organizations. Cengage Learning.

Kissi, J., Dainty, A., \& Liu, A. (2012). Examining middle managers' influence on innovation in construction professional services firms: A tale of three innovations. Construction Innovation, 12(1), 11-28. 
Krause, T. (2007). The effective safety leader: Personality, values and emotional commitment. Occupational Hazards, 69(9), 24.

Martins, E., \& Terblanche, F. (2003). Building organisational culture that stimulates creativity and innovation. European Journal of Innovation Management, 6(1), 64-74.

Martins, E. C., \& Terblanche, F. (2003). Building organisational culture that stimulates creativity and innovation. European Journal of Innovation Management, 6(1), 64-74.

McGuirk, H., Lenihan, H., \& Hart, M. (2015). Measuring the impact of innovative human capital on small firms' propensity to innovate. Research Policy, 44(4), 965-976.

Mishra, P., Bhatnagar, J., Gupta, R., \& Wadsworth, S. M. (2017). How work-family enrichment influence innovative work behavior: Role of psychological capital and supervisory support. Journal of Management \& Organization, 1-23.

Moghimi, S., \& Subramaniam, I. D. (2013). Employees' creative behavior: The role of organizational climate in Malaysian SMEs. International Journal of Business and Management, 8(5), 1.

Moss Kanter, R. (1983). The change masters. New York: Simon \& Schuster Moss.

Moss Kanter, R. (1988). When a thousand flowers bloom: Structural, collective and social conditions for innovation in organization. Research in organizational behavior (Eds), Staw BM and Cummings $L L, 10$.

Mumford, M. D., \& Licuanan, B. (2004). Leading for innovation: Conclusions, issues, and directions. The Leadership Quarterly, 15(1), 163-171.

Nijhof, A., Krabbendam, K., \& Looise, J. C. (2002). Innovation through exemptions: Building upon the existing creativity of employees. Technovation, 22(11), 675-683.

Nybakk, E., Crespell, P., \& Hansen, E. (2011). Climate for innovation and innovation strategy as drivers for success in the wood industry: Moderation effects of firm size, industry sector, and country of operation. Silva Fennica, 45(3), 415-430.

Oldham, G. R., \& Cummings, A. (1996). Employee creativity: Personal and contextual factors at work. Academy of Management Journal, 39(3), 607-634.

Park, Y. K., Song, J. H., Yoon, S. W., \& Kim, J. (2014). Learning organization and innovative behavior: The mediating effect of work engagement. European Journal of Training and Development, 38(1/2), 75-94. 
Podsakoff, P. M., MacKenzie, S. B., \& Organ, D. (2006). Organizational citizenship behavior: Its nature, antecedents, and consequences. Thousand Oaks: Sage Publications.

Pukiene, A. (2016). Innovative work behavior-the role of human resource management and affective commitment. ISM University of Management and Economics.

Rich, B. L., Lepine, J. A., \& Crawford, E. R. (2010). Job engagement: Antecedents and effects on job performance. Academy of Management Journal, 53(3), 617-635.

Sanz-Valle, R., \& Jiménez-Jiménez, D. (2018). HRM and product innovation: Does innovative work behaviour mediate that relationship? Management Decision, 56(6), 1417-1429.

Sarooghi, H., Libaers, D., \& Burkemper, A. (2015). Examining the relationship between creativity and innovation: A meta-analysis of organizational, cultural, and environmental factors. Journal of Business Venturing, 30(5), 714-731.

Sarros, J. C., Cooper, B. K., \& Santora, J. C. (2008). Building a climate for innovation through transformational leadership and organizational culture. Journal of Leadership \& Organizational Studies, 15(2), 145158.

Schaufeli, W. B., \& Bakker, A. B. (2004). Job demands, job resources, and their relationship with burnout and engagement: A multi sample study. Journal of Organizational Behavior, 25(3), 293-315.

Scott, S. G., \& Bruce, R. A. (1994). Determinants of innovative behavior: A path model of individual innovation in the workplace. Academy of Management Journal, 37(3), 580-607.

Shanker, R., Bhanugopan, R., Van der Heijden, B. I., \& Farrell, M. (2017). Organizational climate for innovation and organizational performance: The mediating effect of innovative work behavior. Journal of Vocational Behavior, 100, 67-77.

Shuck, B., \& Wollard, K. (2010). Employee engagement and HRD: A seminal review of the foundations. Human Resource Development Review, 9(1), 89-110.

Si, S., \& Wei, F. (2012). Transformational and transactional leaderships, empowerment climate, and innovation performance: A multilevel analysis in the Chinese context. European Journal of Work and Organizational Psychology, 21(2), 299-320.

Steele, J., \& Murray, M. (2004). Creating, supporting and sustaining a culture of innovation. Engineering, Construction and Architectural Management, 11(5), 316-322. 
Tamayo-Torres, I., Gutiérrez-Gutiérrez, L. J., Llorens-Montes, F. J., \& Martínez-López, F. J. (2016). Organizational learning and innovation as sources of strategic fit. Industrial Management \& Data Systems, $116(8), 1445-1467$.

Unsworth, K. (2001). Unpacking creativity. Academy of Management Review, 26(2), 289-297.

Van de Ven, A. H. (1986). Central problems in the management of innovation. Management Science, 32(5), 590-607.

Van der Vegt, G. S., Van de Vliert, E., \& Huang, X. (2005). Location-level links between diversity and innovative climate depend on national power distance. Academy of Management Journal, 48(6), 1171-1182.

Wagner, R., \& Harter, J. K. (2006). 12: The elements of great managing (Vol. 978): Simon and Schuster.

West, M. A., \& Anderson, N. R. (1996). Innovation in top management teams. Journal of Applied Psychology, 81(6), 680.

Wojtczuk-Turek, A., \& Turek, D. (2015). Innovative behaviour in the workplace: The role of HR flexibility, individual flexibility and psychological capital: The case of Poland. European Journal of Iinnovation Management, 18(3), 397-419.

Wollard, K. K., \& Shuck, B. (2011). Antecedents to employee engagement: A structured review of the literature. Advances in Developing Human Resources, 13(4), 429-446.

Woodman, R. W., Sawyer, J. E., \& Griffin, R. W. (1993). Toward a theory of organizational creativity. Academy of Management Review, 18(2), 293-321.

Zaltman, G., Duncan, R., \& Holbek, J. (1973). Innovations and organizations. John Wiley \& Sons. 